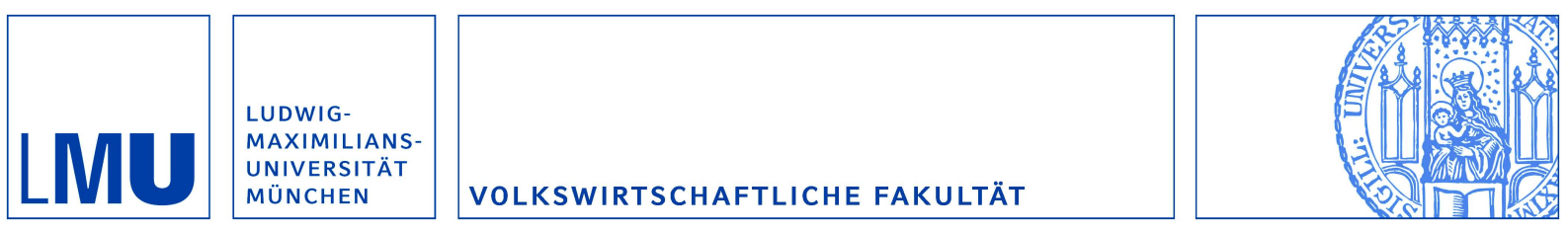

Hauck, Tobias:

Lobbying and the International Fight Against Tax Havens

Munich Discussion Paper No. 2018-4

Department of Economics

University of Munich

Volkswirtschaftliche Fakultät

Ludwig-Maximilians-Universität München

Online at https://doi.org/10.5282/ubm/epub.43213 


\title{
Lobbying and the International Fight Against Tax Havens*
}

\author{
Tobias Hauck ${ }^{\dagger}$
}

April 2018

\begin{abstract}
Despite a variety of measures taken by high tax countries, the international fight against tax havens so far remained rather ineffective. This paper introduces lobbying as a possible explanation for this observation. I analyze the international fight against tax havens in a two country model in which the onshore country exerts pressure on domestic profit shifting firms and the low tax country lobbies against this measure. In this framework, I find that pressure and lobbying are strategic substitutes and that there is an extensive margin incentive for offshore lobbying. I also show that an increase in international integration leads to a decrease in the level of profit shifting, when starting out at high levels of international frictions. Finally, when allowing for a second low tax jurisdiction, the overall level of lobbying increases, but less than proportionally, as free-riding occurs.
\end{abstract}

Keywords: International Taxation, Tax Avoidance, Pressure Policies, Tax Havens, International Lobbying

JEL Codes: H25, H26, F23,

\footnotetext{
*I thank Daniel Gietl, Andreas Haufler and Dominik Sachs for helpful comments and suggestions. Financial support from the German Research Foundation (Research Training Group 1928) is gratefully acknowledged.

†University of Munich, Akademiestr. 1, 80799 München, E-mail: tobias.hauck@econ.lmu.de
} 


\section{Introduction}

In their concluding report for the 2017's G20 Summit, the respective country leaders stressed once again the importance of international tax and financial cooperation (G20 2017 , p. 7-8). In particular, they mention that non-compliant countries, with respect to international tax information exchange, will be put on blacklists. These blacklists are a widely used tool in the fight against tax evasion and profit shifting.

For example, in December 2017, the European Union launched its own blacklist for non cooperative jurisdictions. As of February 2018, nine countries are still found on this list. ${ }^{1}$ Initially, the blacklist consisted of seventeen countries, eight of which were removed by late January 2018. Panama was among these eight countries. ${ }^{2}$ A country which was at the center of public debate in 2016, when investigative journalists disclosed documents from the Panamanian law firm Mossack Fonsecka that used lax regulations to help both firms and individuals to avoid and eventually evade onshore taxation. To be removed from the blacklist, the eight countries only had to make sufficient commitments, backed by letters from high political level, to address previously identified shortcomings (See European Commission 2018). There is no report on additional measure that were taken by either of these eight countries. ${ }^{3}$

In contrast, academic authors have provided empirical evidence for adjustment responses by international investors and therefore limited efficiency of instruments such as blacklists. Johannesen and Zucman (2014) provide evidence for shifting reactions by French deposits from Switzerland to tax havens after the signing of a tax treaty. P. Caruana-Galizia and M. Caruana-Galizia (2016) find such adjustment processes for the European Savings Directive. More specifically, they find a substitution effect in ownership from EU ownership towards non-EU ownership structures following the introduction of the Directive. A third example is given by Gorea (2015), who identifies substitution effects toward other opaque countries if a tax haven signed a tax treaty with the United States.

Furthermore, there is anecdotal evidence regarding international lobbying, especially within supranational institutions. News reports state that several countries within the European Union were reluctant to move forward on talks about a common consolidated corporate tax base (CCCTB), another tool in the fight against intra-EU profit shifting (Smith-Meyer 2017). Generally, the institutional setup of the Council of the European Union is prone to internal lobbying, as proposals on tax matters require unanimity. ${ }^{4}$

\footnotetext{
${ }^{1}$ These countries are American Samoa, Bahrain, Guam, Marshall Islands, Namibia, Palau, Saint Lucia, Samoa and Trinidad and Tobago. As of June 2017, the OECD's blacklist only consisted of one country that was deemed non-compliant: Trinidad and Tobago. See also OECD (2017).

${ }^{2}$ The other countries removed from the list were Barbados, Grenada, the Republic of Korea, Macao SAR, Mongolia, Tunisia and the United Arab Emirates.

${ }^{3}$ Besides blacklists, there are additional tools for onshore countries that are used in the fight against tax havens. Other instruments include (bilateral) tax information exchange agreements (TIEAs), the European Savings Directive that ensures taxation of EU-cross-border interest income for private individuals, or the OECD's "Action Plan on Base Erosion and Profit Shifting" (OECD 2013a,b).

${ }^{4}$ See Boffey (2016) for an example on Great Britain's opposition to put one of its oversea territories onto the EU blacklist.
} 
I aim to explain this discrepancy between the multitude of measures used and their apparent ineffectiveness by employing a theoretical two country model with a three stage game. The main argument is that offshore lobbying, which to my knowledge has thus far not been considered in the theoretical literature, could be another reason for the empirical results and the anecdotal evidence presented.

At the core of this model are two simultaneous choices by the tax revenue maximizing governments that are in stage one and two of the game: The onshore and the offshore country decide about their level of pressure and lobbying respectively, before setting tax rates. Finally, firms with heterogeneous shifting costs decide whether to engage in profit shifting or not.

The onshore government faces two main trade offs. The first one is between setting a higher tax rate to increase revenue, which in turn induces firms to shift profits abroad. The second trade off is associated with the level of pressure set by the onshore government. Higher levels of pressure keep the firms within the onshore country's boundary but lead to higher costs that reduce net tax revenue. The offshore country faces similar trade offs: Increasing its lump sum fee makes the country relatively less attractive for onshore multinationals but it increases tax revenues per profit shifting firm. Furthermore, engaging in costly lobbying effort leads to more firms bringing profits into the country.

The main results of the model are as follows. There exists an extensive margin incentive for tax havens to engage in international lobbying against pressure, when the onshore country does not fully commit to eliminate profit shifting. Then, the first marginal unit of lobbying is beneficial. Each unit of lobbying reduces the marginal benefit of pressure for the onshore country, which leads to lower levels of pressure, resulting in more profit shifting firms. However, if the onshore country commits to eliminate profit shifting, engaging in costly lobbying reduces tax revenue without attracting any taxable profits and thus offshore countries abstain from using the lobbying tool.

Furthermore, when starting at initially low levels of international integration, I find that an increase in integration, as modeled by a decrease in financial frictions, leads to a reduction in the number of profit shifting firms. As the decline in frictions leads to a proportionally higher reduction in the onshore tax rate relative to the reduction in firm specific shifting costs, the marginal firm now finds it optimal to stay onshore rather than to shift profits offshore. The tax rate differential is not sufficiently large to attract this firm anymore, even with lower firm level shifting costs.

When generalizing the model to allow for a second tax haven, the resulting equilibrium pressure level for the onshore country is higher, as the marginal benefit of applying pressure rises. Hence, reducing the number of tax havens can safe the onshore country money. Concerning the tax havens, the overall level of lobbying is higher, while each country's lobbying level falls. The lower country specific level is driven by free-riding. However, the free-riding effect is smaller in size than the mechanical effect of another country joining the lobbying effort.

This analysis is related to three strands of the literature. Firstly, this paper is linked to the literature that discusses international taxation and interest groups. Chu et al. (2015) argue whether the welfare enhancing properties of tax havens are still valid in 
the presence of lobbying. ${ }^{5}$ They furthermore point out that restricting profit shifting abilities might indeed reduce onshore welfare. Additionally, Lai (2010) shows how national interest groups may lead to a rise in capital tax rates following a capital market integration. More generally, Janeba and Schjelderup (2009) show how welfare effects of tax competition are dependent on the national political institutions. ${ }^{6}$

A second strand this paper relates to concerns the various measures used against profit shifting. Bacchetta and Espinosa (1995, 2000) are two seminal contributions with respect to tax information exchange agreements. In their paper from 1995, the authors find that for repeated games, information sharing between governments might be optimal. In their contribution from 2000, they show that in the presence of various reasonable conditions, no exchange agreement of any kind will be reached. Elsayyad (2012) examines the determinants of TIEAs in a generalized Nash bargaining model with cost free onshore pressure. More recently, Dharmapala (2016) examined the effects of the unilateral Foreign Account Tax Compliance Act by the United States. ${ }^{7}$

Onshore pressure policies, i.e. blacklisting and "naming and shaming", are additional tools in the fight against tax havens and have also been discussed. Picard and Pieretti (2011) look at pressure conditions under which offshore financial centers voluntarily comply to monitor their investment. A more general point is made by Elsayyad and Konrad (2012). In their theoretical contribution, they argue why a "big-bang-approach" is more efficient than the sequential approach of closing down tax havens, when facing internationally mobile profits. Konrad and Stolper (2016) stress the importance of individual beliefs in the fight against tax havens. Pieretti and Pulina (2017) have introduced pressure policies as an additional instrument in the fight against tax havens. They argue that real economic activity by onshore multinationals can be sufficiently important for their home government, such that the efficient level of pressure lies below the level that would eliminate profit shifting. The present model builds on the approach by Pieretti and Pulina (2017) but it introduces lobbying by the tax haven to counteract the effects of onshore pressure policies.

Thirdly, there is the empirical literature on the importance of tax havens in international taxation. Desai et al. (2008) argue that tax haven affiliates used by American firms mainly serve two intertwined goals: the aim to allocate taxable income in low-tax jurisdictions and to avoid home country taxation of this income. More generally, Zucman (2013) shows that three-quarters of wealth found in tax havens is off the record and thereby evades taxation. Most recently, Zucman et al. (2017) estimate the global tax

\footnotetext{
${ }^{5}$ If tax havens exhibit positive or negative welfare effects is debated as well: Hong and Smart (2010) find that tax havens create the welfare enhancing possibility for international tax planing. Rose and Spiegel (2007) find that offshore financial centers can have pro-competitive effects on onshore monopolists and Picard and Pieretti (2011) find positive effects for institutional competition. In contrast, Slemrod and Wilson (2009) explain that the presence of tax havens is welfare diminishing.

${ }^{6}$ In a similar vein, Lockwood and Makris (2006) argue that the political decision process might indeed lead to a higher tax rate, following capital market integration.

${ }^{7}$ Empirical contributions in this respect are from Ligthart and Voget (2009) and Bilicka and Fuest (2014). While the latter paper examines the determinants of tax information exchange agreements between countries, the former looks at the determinants for information exchange requests from Dutch tax offices.
} 
revenue loss due to profit shifting to tax havens to be at roughly $€ 200$ billion. Lastly, Alstadsæter et al. (2017) stress the role that tax havens have in fueling wealth inequality.

The remainder of this paper is organized as follows. The following Section introduces the model, its results and the comparative statics. Section 3 gives an extension to the model by incorporating a second tax haven, before Section 4 concludes.

\section{Model}

The model contains two countries $H$ and $F$, denoting the onshore and the offshore country respectively. Furthermore, there is a continuum of firms, all residing in $H$. The firms differ in their reluctance to conduct profit shifting activity, which is captured by the cost parameter $x_{i}$ for firm $i$. This characteristic is uniformly distributed over the $(0,1)$-interval with density $d F(x)$.

A firm that wants to offshore profits also faces transaction costs, e.g. due to internal restructuring, amounting to $k x_{i}$, where $k>0$ represents an inverse measure of international financial integration. The higher $k$, the more frictions are present in the financial market.

If a given firm decides to offshore profits, these profits only face a fixed fee $f_{t} \geq 0$ offshore. This is set by the tax haven's government and represents filing costs and the like. In contrast, in the onshore country, there is a proportional tax rate $t \in[0 ; 1]$ for profits. There is no coordination between the two countries about their tax rates.

Furthermore, the domestic country decides about a level of pressure $\alpha>0$ that is applied to all firms that engage in profit shifting activities. This comes at quadratic costs in the amount of $\frac{\alpha^{2}}{2} g$, where $g$ represents an inverse efficiency parameter of pressure. Assuming that exerting the first unit of pressure is quite easy as multiple measures are still available, marginal costs rise with the number of different measures used ${ }^{8}$

On the contrary, the offshore country decides about how much to lobby. In this context, lobbying is mainly motivated by the setup of most international organizations. Usually, they require a certain threshold among their members for directives or pieces of legislation to pass. For example, in the Council of the European Union, unanimity is required for proposals that touch upon taxation. Lobbying by a tax haven can be thought of as having a seat at this table and thereby influencing the policy outcome, leading to a decrease in onshore pressure. Anecdotal evidence supports this. ${ }^{9}$ Obviously,

\footnotetext{
${ }^{8}$ One way to think about this pressure is decreasing stock prices for firms that are in the news for using tax avoidance strategies. See Hanlon and Slemrod (2009) for a study implicating that stock prices decrease if a firm's aggressive tax behavior is covered in a major news outlet. A second way is to force tax havens to sign TIEAs. Following the introduction of the EU's blacklist, Pierre Moscovici, the EU Commissioner for Economic and Financial Affairs, Taxation, and Customs proposed such an approach (see European Commission 2017).

${ }^{9}$ For example, Smith-Meyer (2017) reports that several countries within the EU, namely the U.K, Sweden and Ireland were reluctant to move forward on talks about the common consolidated corporate tax base (CCCTB), one tool in the course of action against intra-EU profit shifting. Additionally, Boffey (2016) reports on Great Britain's opposition to put its own oversea territory Bermuda, one of Google's main profit hubs, onto an EU blacklist. This lobbying followed the announcement that UK
} 


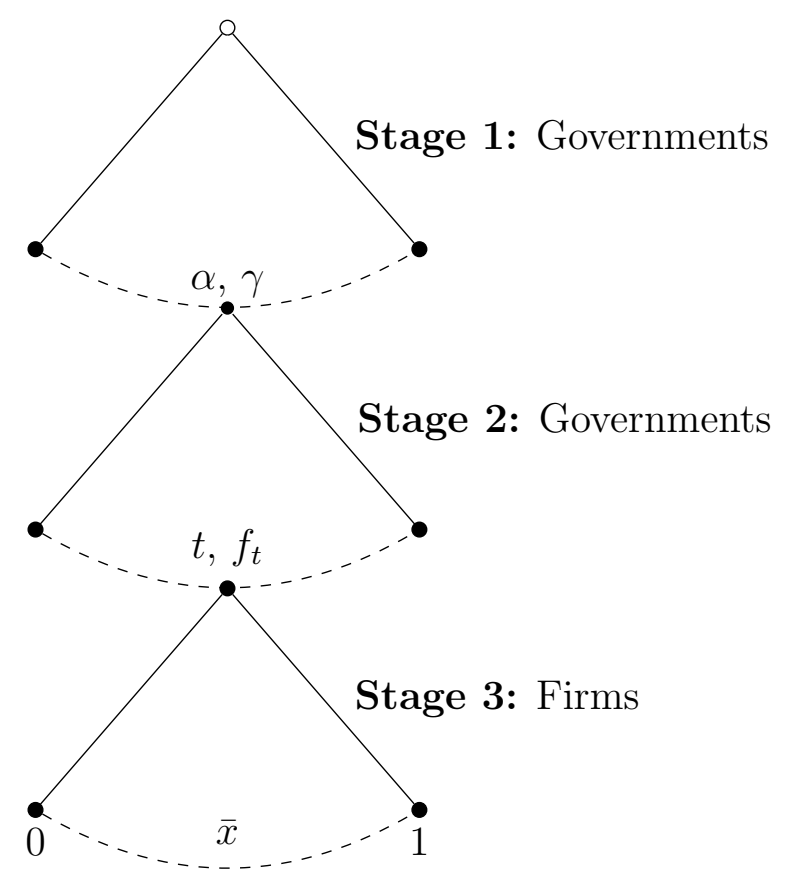

Figure 1: Setup of the game

lobbying is not limited to international institutions only but is also present in bilateral relationships, especially so when the domestic country assumes that the tax haven has a sizeable amount of domestic deposits or enjoys good governance. ${ }^{10}$

In the model, the level of lobbying is inversely given by $\gamma \in[0 ; 1]$, which diminishes the effective pressure costs endured by firms. The lower $\gamma$, the more lobbying takes place. Hence, the effective pressure level endured by firms amounts to $\alpha \gamma$. The associated costs for lobbying are given by $\frac{(1-\gamma)^{2}}{2} \rho$, where $\rho$ is an inverse efficiency measure.

The timing of the model can be seen in Figure 1. In the first stage, governments choose pressure and lobbying, before deciding about tax rates in the second stage. Firms decide in the last stage. This structure is intended to reflect the long term dimension of the decision to become a tax haven. The extent of tax competition following the decision to be a tax haven, given by the tax difference, is a of second order and should therefore succeed the pressure and lobbying decision. ${ }^{11}$

Furthermore, assuming simultaneity for the first two stages is a natural assumption. Any sequential setup that yields a first mover advantage would need an outside the model justification. It remains questionable whether economically relevant onshore countries move first and offshore countries react by lobbying (or setting taxes) afterwards or if

tax officials agreed with Google on back taxes of $£ 130$ million for estimated $£ 7.2$ billion in profits over the previous decade.

${ }^{10}$ Elsayyad (2012) examines this in a generalized Nash-bargaining setup.

${ }^{11}$ Additionally, one can argue that international policies are more time intensive and are therefore more long term in nature. Hence, the sequence of deciding about national policies at a later stage seems sensible. 
well-organized tax havens anticipate the offshore pressuring (tax rate). Thus, I assume simultaneity. As usual, the model is solved by backward induction starting with the last stage.

\subsection{Third stage: Firms' decisions}

In the last stage of the game, firms take the policy parameters as given and only decide whether or not to shift profits abroad. It is assumed that the gross income of any firm is given by $\Pi=s \pi_{x}+h \pi_{x}$, where $s$ represents the immobile share of profits and $h$ the mobile share of profits. Hence, it holds that $s+h=1$.

For the purpose of tax planing, the multinational firm compares the different payoffs: When shifting profits abroad the net profit is $V_{x}^{F}=\pi_{x}-f_{t}-k x_{i}-\alpha \gamma$. The effective level of pressure diminishes the firm's profit directly. The profit in the domestic country is the profit net of the proportional tax: $V_{x}^{H}=(1-t) \pi_{x}$. Without loss of generality, I assume that $\pi_{x}=1$.

Equalizing these two net profit functions yields the marginal profit shifting firm $\bar{x}$, given by

$$
\bar{x}=\frac{t-f_{t}-\alpha \gamma}{k} .
$$

As seen above, the number of profit shifting firms is positively linked with the tax rate differential $t-f_{t}$. The higher it is, the more firms engage in profit shifting. For higher levels of effective pressure $\alpha \gamma$ and for more frictions in the financial market $k$, less firms shift their profits abroad.

It is noteworthy that reactions to changes in the tax rate differential and the effective pressure are scaled by the financial market frictions $k$. The higher is $k$, the lower is the reaction to a change in these parameters. Hence, the higher is $k$, the lower is each firm's elasticity with respect to changes in the tax rates and the effective pressure.

\subsection{Second stage: Tax rates}

In the second stage, both countries decide upon the respective tax rates $t$ and $f_{t}$. Given that firms try to minimize their tax burden by shifting profits, which is associated with tax revenue losses for the onshore country, I assume a Leviathan objective function for the onshore government. While this is a simplification, it implies that for the subset of corporate profits shifted to other country's, the onshore country cares only about repatriating these tax revenues. For other source of tax revenue, the onshore government might pursuit objective functions that take into account onshore citizens' utility. As there are no firms residing in the tax haven, I also assume a tax revenue maximizing strategy for the offshore country, as this is the most important way to generate funds for this government. 
For the onshore country, this yields

$$
\max _{t} W_{H}=\underbrace{t\left[s+h \int_{\bar{x}}^{1} d F(x)\right]}_{\text {Tax revenue }}-\underbrace{\frac{\alpha^{2}}{2} g}_{\text {Pressure costs }} .
$$

The tax revenue in equation (2) is dependent on the immobile share of profits $s$ and the mobile shares $h$ that remain in the country. This is then multiplied by the onshore country's proportional tax rate $t$. Pressure is costly and has to be deducted from the tax revenue.

Applying the uniform distribution property for $x$, plugging in the equilibrium value $\bar{x}$ and taking the first order derivative results in the best response tax rate $t^{b r}$ as follows:

$$
\begin{aligned}
\frac{\partial W_{H}}{\partial t} & =1-h\left[\frac{t-f_{t}-\alpha \gamma}{k}-\frac{t}{k}\right] \stackrel{!}{=} 0 \\
& \Leftrightarrow t^{b r}=\frac{1}{2}\left(\frac{k}{h}+f_{t}+\alpha \gamma\right) .
\end{aligned}
$$

The onshore country's best response function is positively dependent on the level of financial frictions $k$. As lower levels of integration make profit shifting less attractive, the onshore country moves closer to full taxation of profits. This is however scaled by the mobile share of capital, $h$. For high levels of $h$, i.e. a high share of mobile profits, the effect of frictions on the best response tax rate is smaller compared to lower levels of $h$. Hence, the onshore country cares about the size of mobile profits. As both the offshore country's fee $f_{t}$ and the effective pressure level $\alpha \gamma$ diminish the incentives to shift profits offshore, the onshore country's best response tax rate increases.

For the offshore country, welfare computation is similar. The tax revenue function is given by

$$
\max _{f_{t}} W_{F}=\underbrace{f_{t} \int_{0}^{\bar{x}} d F(x)}_{\text {Tax revenue }}-\underbrace{\frac{(1-\gamma)^{2}}{2} \rho}_{\text {Lobbying costs }} .
$$

The first part represents the income from the lump-sum tax for onshore profit shifting activity. The second term are the convex lobbying costs that arise. Again, applying the uniform distribution property for $x$ and plugging in $\bar{x}$ gives the best response lump sum tax rate:

$$
\begin{aligned}
\frac{\partial W_{F}}{\partial f_{t}} & =\left[\frac{t-f_{t}-\alpha \gamma}{k}-\frac{f_{t}}{k}\right] \stackrel{!}{=} 0 \\
& \Leftrightarrow f_{t}^{b r}=\frac{1}{2}(t-\alpha \gamma) .
\end{aligned}
$$

As is seen by equations (5a) and (3a), the tax rates are strategic complements. When plugging one into another, the equilibrium values for both tax rates, $t^{*}$ and $f_{t}^{*}$ can be 
computed. They are given by

$$
t^{*}=\frac{1}{3}\left(2 \frac{k}{h}+\alpha \gamma\right) \quad ; \quad f_{t}^{*}=\frac{\frac{k}{h}-\alpha \gamma}{3}
$$

The comparative statics for these results are quite intuitive. The offshore country's tax rate decreases with increasing effective pressure $\alpha \gamma$ in order to offset the negative effect that an increase of pressure has on the number of profit shifting firms. Quite the opposite holds for the onshore country. More effective pressure leads to higher levels of $t$. If the marginal firm now stays onshore, due to higher $\alpha \gamma$, there is some leeway to increase tax revenue by increasing the tax rate.

The level of shiftable profits $h$ is negatively correlated with both tax rates. An increasing amount of shiftable profits exerts downwards pressure on onshore tax rates. This is seen by inspection of equation (3b). When a large part of the possible tax base is mobile, having a higher tax rate leads to more profits being shifted. Hence, the onshore country reduces its tax rate.

Interestingly, for higher levels of financial frictions, both tax rates rise. This is due to two effects. Firstly, an increase in $k$ increases every firm's costs of shifting profits offshore. Hence, the previously marginal firm now stays onshore. This leads to a pure positive income effect on onshore tax revenue without a change in the tax rate. However, as pointed out previously, an increase in $k$ reduces the elasticity of firms with respect the policy parameters. Therefore, the onshore country finds it optimal to increase the tax rate $t$ further.

For the offshore country, the effect is the opposite. An increase in $k$ reduces the number of firms and leads to a mechanical decrease in tax revenues. However, as the onshore country increases its tax rate, the offshore country can raise its fee as well, while remaining attractive for onshore profit shifting firms.

Finally, $\bar{x}$ can be simplified for further use by plugging in the values obtained in (6) and is given by the following:

$$
\bar{x}=\frac{1}{3 h}-\frac{\alpha \gamma}{3 k} .
$$

The non-negativity constraint for the tax rate in equation (6) and the requirement for a non-negative number of profit shifting firms in equation (7) gives the upper limit of pressure at $\alpha^{u p}=\frac{k}{h} \cdot{ }^{12}$

\subsection{First stage: Pressure and lobbying}

Turning now to the first stage of the game, by incorporating previous results, the onshore country's tax revenue function can be rewritten to

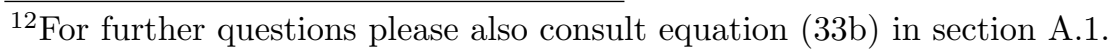




$$
\begin{aligned}
\max _{\alpha} W_{H} & =t^{*}\left[s+h \int_{\bar{x}}^{1} d F(x)\right]-\frac{\alpha^{2}}{2} g=t^{*}[s+1(h-\bar{x})]-\frac{\alpha^{2}}{2} g \\
& \Leftrightarrow \frac{1}{3}\left[2 \frac{k}{h}+\alpha \gamma\right]\left[1-h\left[\frac{1}{3 h}-\frac{\alpha \gamma}{3 k}\right]\right]-\frac{\alpha^{2}}{2} g .
\end{aligned}
$$

Taking the first order derivative and solving for the equilibrium level of pressure thus yields

$$
\begin{aligned}
\frac{\partial W_{H}}{\partial \alpha} & =\frac{4}{9} \gamma+2 \frac{\alpha \gamma^{2} h}{9 k}-\alpha g \stackrel{!}{=} 0 \\
& \Leftrightarrow \alpha^{*}=\frac{\frac{4}{9} \gamma}{g-\frac{2 \gamma^{2} h}{9 k}} .
\end{aligned}
$$

In order to have meaningful results, a sufficiently high level of social costs for applying pressure is assumed, i.e. $g>\frac{2 \gamma^{2} h}{9 k}$. This assumption is sensible, when for example following the arguments by Schjelderup (2016). Tax havens provide secrecy services and therefore increase the costs for onshore governments to tax onshore multinationals' profits. It is a quite regular phenomenon that multinationals adapt their profit shifting tactics, once a previous loophole has been found and closed by the onshore government. Therefore, applying pressure is inherently costly.

If the pressure tool is too cheap, i.e. $g<\frac{2 \gamma^{2} h}{9 k}$, then the benefits of applying further pressure would always outweigh the costs (as is seen in equation (9a)) and lead to the boundary solution of $\bar{x}=0$.

For the offshore country, the welfare function can be rewritten to

$$
\begin{aligned}
\max _{\gamma} W_{F} & =f_{t} \int_{0}^{\bar{x}} d f(x)-\frac{(1-\gamma)^{2}}{2} \rho=f_{t} \bar{x}-\frac{(1-\gamma)^{2}}{2} \rho \\
& \Leftrightarrow \frac{1}{3}\left[\frac{k}{h}-\alpha \gamma\right]\left(\frac{1}{3 h}-\frac{\alpha \gamma}{3 k}\right)-\frac{(1-\gamma)^{2}}{2} \rho .
\end{aligned}
$$

Taking the first order derivative and solving for the optimal level of lobbying yields

$$
\begin{aligned}
& \frac{\partial W_{F}}{\partial \gamma}=2 \gamma \frac{\alpha^{2}}{9 k}+(1-\gamma) \rho-\frac{2}{9 h} \alpha \stackrel{!}{=} 0 \\
& \Leftrightarrow \gamma^{*}=\frac{9 k h \rho-2 \alpha k}{9 k h \rho-2 \alpha^{2} h}=1-\frac{2 \alpha k-2 \alpha^{2} h}{9 k h \rho-2 \alpha^{2} h} .
\end{aligned}
$$

For this equilibrium level of lobbying to be within the interval between zero and one, sufficiently high costs of lobbying for the offshore country are assumed. ${ }^{13}$ When examining (11b) one can see that if $\alpha=\alpha^{u p}=\frac{k}{h}$, the second term vanishes. However,

\footnotetext{
${ }^{13}$ See section A.1 in the Appendix for more information on this.
} 
for $\alpha<\alpha^{u p}$, the second term is larger then zero and there exists an extensive margin incentive for the offshore country to conduct lobbying. This is summarized in Proposition 1:

Proposition 1. Given that the onshore country cannot commit to fully eliminate profit shifting, there is an extensive margin incentive for the offshore country to engage in lobbying against the onshore country's pressure.

Intuitively, the result is not surprising. Given that the onshore country commits to eliminate profit shifting with setting $\alpha^{u p}$, there is no tax revenue from profit shifting. Engaging in costly lobbying activities is therefore strictly dominated by not doing anything, i.e. $\gamma=1$.

If this not the case, at least the first marginal unit of lobbying is beneficial for the offshore country. Hence, given that the onshore country does not fully commit to eliminate profit shifting, offshore lobbying is worthwhile. While this result was in a two-country setup, section 3 examines whether there are additional effects if there are multiple tax havens involved. For now, the comparative statics of this model is also insightful.

\subsection{Comparative statics}

As regards comparative statics, the change in financial integration $(k)$ as well as an efficiency change in the offshore cost effectiveness $(\rho)$ and the onshore costs $(g)$ are examined. As the previous results are not given explicitly, the implicit function theorem is applied.

The matrix of second order (cross-) derivatives is given by $|D|$ :

$$
|D|=\left|\begin{array}{ll}
\frac{\partial^{2} W_{H}}{\partial \alpha^{2}} & \frac{\partial^{2} W_{H}}{\partial \alpha \partial \gamma} \\
\frac{\partial^{2} W_{F}}{\partial \gamma \partial \alpha} & \frac{\partial W_{F}^{2}}{\partial \gamma^{2}}
\end{array}\right|=\left|\begin{array}{cc}
\frac{2 \gamma^{2} h}{9 k}-g & \frac{4}{9}+\frac{4 \alpha \gamma h}{9 k} \\
-\frac{2}{9 h}+\frac{4 \alpha \gamma}{9 k} & \frac{2 \alpha^{2}}{9 k}-\rho
\end{array}\right| .
$$

Throughout, I assume that direct effects outweigh indirect effects and thus $|D|>0 .{ }^{14}$

Onshore cost efficiency $g$ As regards the onshore pressure costs, comparative static results are in line with regular expectations. As seen in equation (13), an increase in the cost of the pressure policy tool is associated with a decrease in the usage of this policy instrument.

$$
\frac{\partial \alpha^{*}}{\partial g}=\frac{\left|\begin{array}{ll}
-\frac{\partial^{2} W_{H}}{\partial \alpha \partial g} & \frac{\partial^{2} W_{H}}{\partial \alpha \partial \gamma} \\
-\frac{\partial^{2} W_{F}}{\partial \gamma \partial g} & \frac{\partial^{2} W_{F}}{\partial \gamma^{2}}
\end{array}\right|}{|D|}=\frac{\left|\begin{array}{cc}
\alpha & \frac{4}{9}+\frac{4 \alpha \gamma h}{9 k} \\
0 & \frac{2 \alpha^{2}}{9 k}-\rho
\end{array}\right|}{|D|}<0 .
$$

For the offshore country, the result is the opposite. An increase in the other country's policy instrument and the associated decrease of its usage leads to an increase in the

\footnotetext{
${ }^{14}$ See A.2 in the Appendix for more comments.
} 
amount of lobbying that the offshore country applies.

$$
\frac{\partial \gamma^{*}}{\partial g}=\frac{\left|\begin{array}{cc}
\frac{2 \gamma^{2} h}{9 k}-g & \alpha \\
-\frac{2}{9 h}+\frac{4 \alpha \gamma}{9 k} & 0
\end{array}\right|}{|D|}<0 .
$$

Offshore cost efficiency $\rho$ The effect for an increase in the costs for offshore lobbying is unambiguous for both $\alpha$ and $\gamma$.

$$
\frac{\partial \gamma^{*}}{\partial \rho}=\frac{\left|\begin{array}{cc}
\frac{2 \gamma^{2} h}{9 k}-g & 0 \\
-\frac{2}{9 h}+\frac{4 \alpha \gamma}{9 k} & -(1-\gamma)
\end{array}\right|}{|D|}>0 .
$$

Remembering that the first cell in the top left corner is negative, it holds that the main diagonal is positive. Hence, the overall effect is positive, i.e. there is less lobbying. Thus, if the policy instrument becomes more expensive, the government is reluctant to use it. For the equilibrium level of pressure things look like this:

$$
\frac{\partial \alpha^{*}}{\partial \rho}=\frac{\left|\begin{array}{cc}
0 & \frac{4}{9}+\frac{4 \alpha \gamma h}{9 k} \\
-(1-\gamma) & \frac{2 \alpha^{2}}{9 k}-\rho
\end{array}\right|}{|D|}>0 .
$$

An increase in the level of offshore lobbying costs increases the level of onshore pressure. The onshore country anticipates the lower level of lobbying and therefore finds it optimal to apply more pressure to keep more firms within its boundary.

To sum those two parts up, it is striking to see that the level of pressure and the level of lobbying are strategic substitutes. If the cost for one policy parameter increases, the respective measures is used less intensively. In turn, the other country's measure is used more intensively. Along the arguments from Bulow et al. (1985), a decrease of the other country's policy tool due to higher costs leads to an increase in the marginal benefit for the country not affected by the cost increase. Hence, the latter finds it beneficial to increase the use of its policy parameter until the first order condition holds again. In different words, an increase in one country's cost of the policy tool is directly affecting its own marginal benefit and indirectly affecting the other country's marginal benefit..

Financial integration $k$ The most interesting comparative statics result is by looking at a change in frictions in the international financial market, hence a change in $k .{ }^{15}$ For the onshore country this yields

$$
\frac{\partial \alpha^{*}}{\partial k}=\frac{\left|\begin{array}{cc}
\frac{2 \alpha \gamma^{2} h}{(9 k)^{2}} & \frac{4}{9}+\frac{4 \alpha \gamma h}{9 k} \\
\frac{2 \alpha^{2} \gamma}{(9 k)^{2}} & \frac{2 \alpha^{2}}{9 k}-\rho
\end{array}\right|}{|D|}<0 .
$$

${ }^{15}$ Note that I consider an increase in financial frictions (increase in $k$ ), the opposite is true for a decrease in financial frictions, a decrease in $k$. The latter is what people usually refer to as economic integration. 
Note that the equilibrium tax rate $t^{*}$ as given by equation (6) is an increasing function in $k$. Therefore, if $k$ increases, so does the onshore tax rate, which in turn increases each firm's incentive for shifting profits. This increase in $t^{*}$ for all firms outweighs the cost increase in firm specific costs $k x_{i}$ that has made the marginal firm abstaining from profit shifting. Hence the onshore country cuts back on pressure.

$$
\frac{\partial \gamma^{*}}{\partial k}=\frac{\left|\begin{array}{cc}
\frac{2 \gamma^{2} h}{9 k}-g & \frac{2 \alpha \gamma^{2} h}{(9 k)^{2}} \\
-\frac{2}{9}+\frac{4 \alpha \gamma h}{9 k} & \frac{2 \alpha^{2} \gamma}{(9 k)^{2}}
\end{array}\right|}{|D|}<0 .
$$

For the offshore country, the effect is opposite. An increase in the financial frictions makes the offshore country relatively attractive, as the tax rate differential $t-f_{t}$ increases. Hence, there are more incentives for onshore firms to shift profits. Nonetheless, the offshore country also increases its tax rate $\frac{\partial f_{t}^{*}}{\partial k}>0$, as seen in equation (6). This increase in tax revenue releases further funds for increasing lobbying and thus makes the offshore country even more attractive.

Obviously, the effects are reversed for reductions in $k$. This means that with a higher degree of globalization, the onshore country intensifies its pressure $\left(\frac{\partial \alpha^{*}}{\partial-k}>0\right)$ and the offshore country lobbies less $\left(\frac{\partial \gamma^{*}}{\partial-k}>0\right)$. This is particularly interesting, when one looks at the number of firms that are engaged in profit shifting and how this changes with higher levels of globalization.

Number of profit shifting firms The effect of financial integration on the equilibrium level of profit shifting firms, i.e. the total derivative of $\bar{x}$ with respect to $-k$, is the following:

$$
\begin{aligned}
\frac{d \bar{x}}{d-k} & =\frac{d\left(\frac{1}{3 h}+\frac{\alpha \gamma}{-3 k}\right)}{d-k} \\
& =\frac{-3 k\left(\alpha \frac{\partial \gamma}{\partial-k}+\gamma \frac{\partial \alpha}{\partial-k}\right)+3 \alpha \gamma}{(-3 k)^{2}} \\
& =\frac{\alpha \gamma-k\left(\alpha \frac{\partial \gamma}{\partial-k}+\gamma \frac{\partial \alpha}{\partial-k}\right)}{9 k^{2}} \lesseqgtr 0 .
\end{aligned}
$$

As seen above, the resulting effect is crucially dependent on the existing level of financial market frictions $k$. Remember that there are two effects at work, when $k$ decreases. Firstly, the elasticity of firms with respect to the tax rate increases and thus, the onshore country will set a lower tax rate. Secondly, there is a mechanical cost reduction effect on the firm level, as $k x_{i}$ falls. While the first leads the firms to stay onshore, the second one does the opposite. Hence there exists a cut-off point $\hat{k}$ below which, a reduction in financial frictions leads to more profit shifting. This cut-off is given by

$$
\hat{k}=\frac{\alpha \gamma}{\alpha \frac{\partial \gamma}{\partial-k}+\gamma \frac{\partial \alpha}{\partial-k}} .
$$


Therefore, international integration need not necessarily be bad for the onshore country. When the indirect effect associated with international integration, namely a lower tax rate, is sufficiently larger than the direct cost reduction for firms, then there is a possibility for a lower number of profit shifting firms. On the contrary, when the effect of a reduction in $k$ on the individual firm level (via the heterogeneous costs) outweighs the effect of the change in economic environment, there will be more profit shifting. This is true for a reduction of low values of $k$. This is summarized in Proposition 2:

Proposition 2. If the level of international frictions is sufficiently large, $k>\hat{k}, a$ marginal reduction in frictions decreases the number of profit shifting firms. On the contrary, if $k<\hat{k}$, more financial integration results in a higher number of profit shifting firms.

\section{Multiple tax havens}

\subsection{General remarks and third stage}

While the previous section has been insightful to analyze fundamental issues for one tax haven, it is worthwhile to consider a more generalized setup by allowing for a second tax haven. The main question now is whether the sum of the individual country's lobbying levels is larger than the lobbying effort in the initial setup. Furthermore, the second insight is to examine whether the onshore country's pressure level rises or decreases, relative to the case with one tax haven.

To this end, I employ a generalized version of the previous model. Now, firm profits are divided up between three countries. There is a fraction $s$ that is immobile and two shares $h_{1}$ and $h_{2}$ that are bilaterally mobile to the respective tax havens $F_{l}$ and $F_{m}$, $m, l=(1,2) \cdot{ }^{16}$ It holds that $1=s+h_{1}+h_{2}$.

The second modification is the cost structure of the firms, now denoted by $\zeta_{i}=$ $\left(\begin{array}{l}x_{i}^{1} \\ x_{i}^{2}\end{array}\right)$, indicating the firm specific costs of shifting parts of their profits to either of the two tax havens. ${ }^{17}$ For the sake of simplicity, I assume that financial frictions are the same worldwide. Furthermore, I assume that the pressure exerted cannot be varied on the country level. While this is a restricting assumption, there are valid reasons why countries cannot discriminate between tax havens. ${ }^{18}$ The potential profits of each firm

\footnotetext{
${ }^{16}$ I abstract from fully mobile profit shares. See e.g. Elsayyad and Konrad (2012) for the examination of a very closely related case with fully mobile capital.

${ }^{17} \mathrm{I}$ do not assume any form of correlation between the two cost parameters within a firm.

${ }^{18}$ When looking at country's on blacklists, such as the OECD's, there is no way to discriminate between countries that are within one category such as e.g. being "non-compliant". Secondly, as regards TIEAs, most countries follow the OECD's model protocol. The low variety in the scope of TIEAs supports this idea.
} 


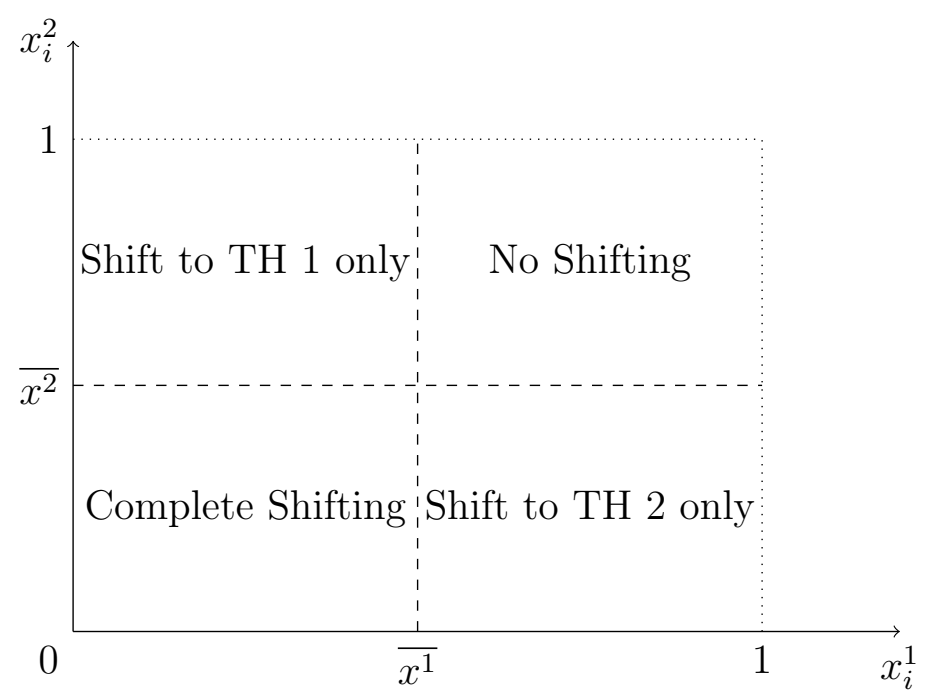

Figure 2: Distribution of firms into the different profit shifting schemes

are then given as follows

$$
\Pi\left(\begin{array}{c}
x_{i}^{1} \\
x_{i}^{2}
\end{array}\right)= \begin{cases}(1-t)\left(s+h_{1}+h_{1}\right) & \text { if } x_{i}^{1} \in\left(\overline{x^{1}} ; 1\right) \& x_{i}^{2} \in\left(\overline{x^{2}} ; 1\right) \\
(1-t)\left(s+h_{2}\right)+\left(1-f_{t 1}-\alpha \gamma_{1}-k x_{i}^{1}\right) h_{1} & \text { if } x_{i}^{1} \in\left(0 ; \overline{x^{1}}\right] \& x_{i}^{2} \in\left(\overline{x^{2}} ; 1\right) \\
(1-t)\left(s+h_{1}\right)+\left(1-f_{t 2}-\alpha \gamma_{2}-k x_{i}^{2}\right) h_{2} & \text { if } x_{i}^{1} \in\left(\overline{x^{1}} ; 1\right) \& x_{i}^{2} \in\left(0 ; \overline{x^{2}}\right] \\
(1-t)(s)+\left(1-f_{t 1}-\alpha \gamma_{1}-k x_{i}^{1}\right) h_{1} & \text { if } x_{i}^{1} \in\left(0 ; \overline{x^{1}}\right] \& x_{i}^{2} \in\left(0 ; \overline{x^{2}}\right] \\
+\left(1-f_{t 2}-\alpha \gamma_{2}-k x_{i}^{2}\right) h_{2} & \end{cases}
$$

where the cutoffs are given by

$$
\overline{x^{1}}=\frac{t-f_{t 1}-\alpha \gamma_{1}}{k}, \overline{x^{2}}=\frac{t-f_{t 2}-\alpha \gamma_{2}}{k} .
$$

The intuition for the different profits in equation (21) is fairly obvious. As the profit shifting decision into one country is distinct from the shifting decision into the second country, firms will face a choice set of four actions.

When the firm is neither efficient in shifting profits into haven one nor into haven two, all profits will remain in the onshore country (first line). The second line describes the case in which the firm finds it optimal to shift some profits to $F_{1}$ but not to $F_{2}$. The third line represents just the opposite case. In the last case, firms shift all mobile profits to the respective haven. Thus, only the complete immobile share of profits remains at home. This is summarized graphically in Figure 2.

\subsection{Second and first stage}

The tax revenue functions as previously given by equation (2) and (4) is extended to 


$$
\begin{aligned}
\max _{t} W_{H} & =t[s]+t\left[h_{1} \int_{\overline{x^{1}}}^{1} d F\left(x_{i}^{1}\right)+h_{2} \int_{\overline{x^{2}}}^{1} d F\left(x_{i}^{2}\right)\right] \\
& \left.\Leftrightarrow t\left[s+\left(1-\overline{x^{1}}\right) h_{1}+\left(1-\overline{x^{2}}\right) h_{2}\right)\right] .
\end{aligned}
$$

There are now two different mobile parts of the onshore multinational's profit that have weights $h_{1}$ and $h_{2}$. For the individual tax haven $l$, the welfare function looks very similar to the one seen in the previous part:

$$
\begin{aligned}
\max _{f_{t l}} W_{F_{l}} & =f_{t l} \int_{0}^{\overline{x^{l}}} d F\left(x_{i}^{l}\right)-\frac{\left(1-\gamma_{l}\right)^{2}}{2} \rho_{l} \\
& \Leftrightarrow f_{t l}\left[\overline{x^{l}}\right]-\frac{\left(1-\gamma_{l}\right)^{2}}{2} \rho_{l} .
\end{aligned}
$$

Solving for the first order conditions and the plugging in the equilibrium values into one another yields the optimal onshore tax rate $\tilde{t}^{*}$ and the optimal offshore lump sum fee $\tilde{f}_{t l}^{*}$. These are given by:

$$
\begin{aligned}
\tilde{t^{*}} & =\frac{1}{3\left(h_{1}+h_{2}\right)}\left[2 k+\alpha \gamma_{1} h_{1}+\alpha \gamma_{2} h_{2}\right] \\
\tilde{f}_{t l}^{*} & =\frac{1}{6\left(h_{l}+h_{m}\right)}\left[2 k-2 \alpha \gamma_{l} h_{l}+\alpha h_{m}\left[\gamma_{m}-3 \gamma_{l}\right]\right]
\end{aligned}
$$

The equilibrium onshore tax rate $\tilde{t^{*}}$ is still positively associated with higher levels of effective pressure. It is however striking that the individual offshore lump sum fee for country $l$ is now also dependent on the actions by country $m$. When assuming symmetric countries in terms of their lobbying, i.e. $\gamma_{m}=\gamma_{l}$, then the negative spillover on the fee by country $l$ prevails, as the interior bracket turns negative. However, when countries are quite different and residing lobbying levels vary such that $3 \gamma_{l}>\gamma_{m}$, then there is an overall positive effect from the other country. ${ }^{19}$ Put differently, the high lobbying effort by country $l$ allows tax haven $m$ to increase its lump sum fee.

The resulting number of profit shifting firms is given by

$$
\overline{x^{l}}=\frac{1}{3\left(h_{l}+h_{m}\right)}-\frac{1}{2\left(h_{l}+h_{m}\right)}\left[\frac{2 \alpha \gamma_{l} h_{l}+\alpha h_{m}\left[3 \gamma_{l}-\gamma_{m}\right]}{3 k}\right] .
$$

For the equilibrium number of profit shifting firms, there is again a spillover effect of the other country's lobbying. For the benchmark case of symmetric tax havens, i.e. $\gamma_{l}=\gamma_{m}$, the bracket remains positive, i.e. the positive effect of the own lobbying

\footnotetext{
${ }^{19}$ For example, it might be the case that there is one tax haven which has significantly low costs of lobbying and therefore lobbies quite intensively. The offshore country with high costs benefits from this by being able to set a higher lump sum fee.
} 
prevails. However, when the difference in lobbying levels is rather pronounced, $\gamma_{m}>3 \gamma_{l}$, the bracket becomes negative.

Note that this bracket is reversed to the interior bracket seen in equation (25). This is quite intuitive. Assuming that $\gamma_{m}>3 \gamma_{l}$, i.e. country $l$ experiences a large spillover effect for the lump sum fee, thus it finds it optimal to raise this fee. In turn, this reduces the number of firms that shift profits to this country, as higher fees make profit shifting to this shore less attractive. This last point is observed in equation (27). Furthermore, note that equation (27) nests the single tax haven number of profit shifting firms as given by equation (7), when we assuming equal lobbying levels $\left(\gamma_{l}=\gamma_{m}\right)$ and $h=h_{l}+h_{m}$.

When turning to the first stage of the game, I assume symmetric offshore countries for the sake of simplicity. Symmetry hereby refers to both countries enjoying the same share of attainable profits, $h_{m}=h_{l}$, and the same cost effectiveness of lobbying, $\rho_{l}=\rho_{m}$. This in turn implies that both countries will set the same level of lobbying. Hence, examining one tax haven is sufficient. Following the tax revenue maximization approaches given in equations (23) and (24), this yields the following level of offshore lobbying, $\tilde{\gamma}^{*}$, that is efficient for each tax haven:

$$
\tilde{\gamma}^{*}=\frac{9 k \rho h-1.25 k \alpha}{9 k \rho h-2.5 \alpha^{2} h} .
$$

Furthermore, the equilibrium pressure level of the onshore country for the case of multiple tax havens, $\tilde{\alpha}^{*}$, is given by

$$
\tilde{\alpha^{*}}=\frac{\frac{4}{9} h \gamma^{2}}{g-\frac{2 \gamma^{2} h}{9 k}} .
$$

\subsection{Comparison to the single tax haven case}

As the equilibrium values of pressure and lobbying in the presence of multiple tax havens are given, a comparison whether these levels are larger or smaller in size is insightful.

Equilibrium pressure level For the equilibrium pressure level, the comparison is as follows:

$$
\tilde{\alpha}^{*}=\frac{\frac{4}{9} \gamma}{g-\frac{3 \gamma^{2} h}{9 k}}>\alpha^{*}=\frac{\frac{4}{9} \gamma}{g-\frac{2 \gamma^{2} h}{9 k}} .
$$

As is seen in equation (30), for a given level of lobbying, the level of pressure applied in the two tax haven case is higher than in the case with only one tax haven. Mathematically, this is seen by the smaller denominator for $\tilde{\alpha}^{*}$ relative to $\alpha^{*}$.

As onshore pressure and offshore lobbying are strategic substitutes, there is an incentive for the onshore government to set a higher level of pressure, when facing multiple tax havens. This is as an increase in onshore lobbying now reduces the marginal benefit of lobbying for more than one tax haven. Therefore, a higher level of pressure relative to the case with only one tax havens is used. Proposition 3 summarizes this: 
Proposition 3. For a given aggregate level of lobbying by two symmetric offshore countries, there is more pressure applied by the onshore country relative to a case with only one tax haven.

Equilibrium lobbying level Equally interesting is how the equilibrium value of lobbying will be for a given tax haven compared to the initial case of one tax haven:

$$
\tilde{\gamma^{*}}=\frac{9 k \rho h-1.25 \alpha k}{9 k \rho h-2.5 \alpha^{2} h}>\frac{9 k \rho h-2 \alpha k}{9 k \rho h-2 \alpha^{2} h}=\gamma^{*} .
$$

For a given level of pressure $\alpha$, there is less lobbying per country, $\tilde{\gamma}^{*}$ is larger, in the case with multiple tax havens than in the case with one tax haven. However, it can be shown that the aggregate level of lobbying still increases $\left(2\left(1-\tilde{\gamma}^{*}\right) \geq\left(1-\gamma^{*}\right)\right)$. This is summarized in the following Proposition:

Proposition 4. Given a certain level of pressure by an onshore country, there is less lobbying per country in the case with multiple tax havens, relative to the case with one tax haven only. However, aggregate lobbying increases.

The reason thereof is closely related to a public good problem: For the case of one tax haven, $\gamma^{*}$ is optimal. However, when a second tax haven enters the game, there is a free-riding incentive for the first tax haven. The first offshore country anticipates that the second country also contributes some lobbying. As I assume symmetric countries, both countries each contribute the same level that is below the efficient level for the single tax haven case, however, this effect is of second order relative to the mechanical doubling of lobbying efforts.

From an intuitive point of view this seems likely as well. If there are two countries in a supranational organization that both lobby for the existence of tax havens, individual efforts need not to be as big as if there was only one country lobbying. At the same time, the overall effort is bigger. 


\section{Conclusion}

In this paper, I have emphasized the role of international lobbying in the fight against tax havens. To this end, I employed a three stage, two country model in which the onshore country and offshore country decide about pressure and lobbying before setting their respective tax rates. Lastly, onshore multinational firms decide whether to shift profits or not.

In this context, international lobbying is found to decrease the onshore country's benefit to apply pressure and is thus an important tool used by offshore countries to attenuate the negative effects associated with pressure. Only in rare cases, when onshore governments are over proportionally efficient and able to credibly commit to eliminate profit shifting, there is no lobbying. If this is not the case, there exists some lobbying.

This result helps to explain the puzzle that despite agreeing to comply with requirements in order to be taken off blacklists, there remains scope for international profit shifting by multinational firms. This is the case, as the effective level of pressure endured by firms is significantly below the level intended by the onshore governments.

Furthermore, I show that early stages of international integration might potentially reduce profit shifting, if general tax incentives change at a relatively high pace. Economic integration exerts more pressure on the level of onshore taxation than it reduces profit shifting incentives. Assuming that this threshold has already been passed, further improving capital mobility within Europe will fuel profit shifting. In this respect, accessions to the European Union may give rise to suitable setups to empirically examine a reduction in international frictions and to confirm the theoretical predictions.

When generalizing the model to allow for a second tax haven, there is evidence that an adding up effect of lobbying takes place. Despite some free-riding among tax havens, the overall lobbying that onshore countries face is higher than in the case with only one tax haven. For an increasing number of tax havens, the onshore country also increases its pressure level, as the marginal benefit of pressure is higher than in the case with one haven only.

Starting from these new results, there is ample scope for future research. One example could be an examination of a generalized model with heterogeneous offshore countries, as defined by their obtainable share of profits. Here, one might assume that heterogeneity in tax haven size leads to an increase in the level of pressure applied, relative to the original case. Furthermore, regarding potential free-riding within international organizations, adding a second onshore country promises useful insights. 


\section{References}

Alstadsæter, Annette, Niels Johannesen, and Gabriel Zucman (2017). "Tax Evasion and Inequality." NBER Working Paper No. 23772.

Bacchetta, Philippe and Maria Paz Espinosa (1995). "Information sharing and tax competition among governments." Journal of International Economics 39, 103-121.

- (2000). "Exchange-of-information clauses in international tax treaties." International Tax and Public Finance 7, 275-293.

Bilicka, Katarzyna and Clemens Fuest (2014). "With which countries do tax havens share information." International Tax and Public Finance 21, 175-197.

Boffey, Daniel (2016). Tories lobbying to protect Google’s £30bn island tax haven. The Guardian online. https : / / www . theguardian . com / technology / 2016 / jan / 30 / google-tory-battle-protect-30bn-tax-haven-bermuda. (last accessed: 17/07/2017).

Bulow, Jeremy I., John D. Geanakoplos, and Paul D. Klemperer (1985). "Multimarket Oligopoly: Strategic Substitutes and Complements." Journal of Political Economy 93, 488-511.

Caruana-Galizia, Paul and Matthew Caruana-Galizia (2016). "Offshore financial activity and tax policy: evidence from a leaked data set." Journal of Public Policy 36, 457-488.

Chu, Hsun, Chu-Chuan Cheng, and Yu-Bong Lai (2015). "A political economy of tax havens." International Tax and Public Finance 22, 956-976.

Desai, Mihir A., C. Fritz Foley, and James R. Hines (2008). "The demand for tax haven operations." Journal of Public Economics 90, 513-531.

Dharmapala, Dhammika (2016). "Cross-border tax evasion under a unilateral FATCA regime." Journal of Public Economics 141, 29-37.

Elsayyad, May (2012). "Bargaining over Tax Information Exchange." Max Plack Institute for Tax Law and Public Finance Working Paper 2012-2.

Elsayyad, May and Kai A. Konrad (2012). "Fighting multiple tax havens." Journal of International Economics 86, 295-305.

European Commission (Dec. 2017). Fair Taxation: EU publishes list of non-cooperative tax jurisdictions. http://europa.eu/rapid/press-release_IP-17-5121_en.htm. (last accessed: 13/02/2018).

-(Jan. 2018). Taxation: Eight jurisdictions removed from EU list . http : / / www . consilium . europa. eu/en/press/press-releases/2018/01/23/taxation-eightjurisdictions-removed-from-eu-list/. (last accessed: 13/02/2018).

G20 (2017). "G20 Leader's Declaration - Shaping an interconnected world." https : //www . g20 . org/gipfeldokumente/G20-leaders-declaration . pdf (last accessed: 14/07/2017).

Gorea, Denis (2015). "Catch Me If You Can: U.S. Tax Treaties and Shifts in Offshore Investments." mimeo. 
Hanlon, Michelle and Joel Slemrod (2009). "What does tax aggressiveness signal? Evidence from stock price reactions to news about tax shelter involvement." Journal of Public Economics 93, 126-141.

Hong, Qing and Michael Smart (2010). "In praise of tax havens: International tax planning and foreign direct investment." European Economic Review 54, 82-95.

Janeba, Eckhard and Guttorm Schjelderup (2009). "The Welfare Effects of Tax Competition Reconsidered: Politicians and Political Institutions." The Economic Journal 119, 1143-1161.

Johannesen, Niels and Gabriel Zucman (2014). "The End of Bank Secrecy? An Evaluation of the G20 Tax Haven Crackdown." American Economic Journal: Economic Policy 6, 65-91.

Konrad, Kai A. and B.M. Stolper Tim (2016). "Coordination and the fight against tax havens." Journal of International Economics 103, 96-107.

Lai, Yu-Bong (2010). "The political economy of capital market integration and tax competition." European Journal of Political Economy 26, 475-487.

Ligthart, Jenny E. and Johannes Voget (2009). "The determinants of cross-border tax information sharing: A panel data analysis." mimeo.

Lockwood, Ben and Miltiadis Makris (2006). "Tax incidence, majority voting and capital market integration." Journal of Public Economics 90, 1007-1025.

OECD (2013a). Action Plan on Base Erosion and Profit Shifting. Paris: OECD Publishing.

- (2013b). Adressing Base Erosion and Profit Shifting. Paris: OECD Publishing.

- (2017). "Brief on the State of Play on the international tax transparency standards." http: //www . oecd.org/tax/transparency/brief-and-FAQ-on-progress-on-taxtransparency.pdf (last accessed: 14/07/2017).

Picard, Pierre M. and Patrice Pieretti (2011). "Bank secrecy, illicit money and offshore financial centers." Journal of Public Economics 95, 942-955.

Pieretti, Patrice and Giuseppe Pulina (2017). "Tax havens under international pressure: How do they react?" mimeo.

Rose, Andrew K. and Mark M. Spiegel (2007). "Offshore Financial Centers: Parasites or Symbionts?" The Economic Journal 117, 1310-1335.

Schjelderup, Guttorm (2016). "Secrecy jurisdictions." International Tax and Public Finance 23, 168-189.

Slemrod, Joel and John D. Wilson (2009). "Tax competition with parasitic tax havens." Journal of Public Economics 93, 1261-1270.

Smith-Meyer, Bjarke (2017). EU's idea for tackling tax avoidance? Blame others. Politico online. http : / / www . politico . eu / article / eus-idea-for-tackling-taxavoidance-blame-others/. (last accessed: 17/07/2017).

Zucman, Gabriel (2013). "The missing wealth of Nations: Are Europe and the U.S. net debtors or net creditors?" Quarterly Journal of Economics 128, 1321-1364. 
Zucman, Gabriel, Thomas Tørsløv, and Ludvig Wier (2017). €600 Billion and Counting: Why High Tax Countries Let Tax Havens Flourish. http: / / gabriel-zucman . eu / files/TWZ2017.pdf. (last accessed: 12/12/2017). 


\section{A. Appendix}

\section{A.1. Full pressure efficiency and properties of $\gamma^{*}$}

Efficiency of $\alpha^{u p}$ This section shows why equation (11) leads to $\gamma^{*}=1$ if $\alpha=\alpha^{u p}$, i.e. if the onshore country uses the upper boundary of pressure, there is no lobbying by the offshore country. Taking equation (11b) as a starting point, one can plug in the upper boundary level of pressure found previously, $\alpha^{u p}=\frac{k}{h}$ :

$$
\begin{aligned}
& \gamma^{*}=\frac{9 k h \rho-2 \alpha k}{9 k h \rho-2 \alpha^{2} h} \\
& \Leftrightarrow \gamma=\frac{9 k h \rho-2 \frac{k}{h} k}{9 k h \rho-2\left(\frac{k}{h}\right)^{2} h} \\
& \Leftrightarrow \gamma\left[9 k h \rho-2 \frac{k^{2}}{h^{2}} h\right]=9 k h \rho-2 \frac{k}{h} k \\
& \Leftrightarrow 9 k h \rho \gamma-2 \frac{k^{2}}{h}=9 k h \rho-2 \frac{k^{2}}{h}
\end{aligned}
$$

As the second part on both sides evaporates, the last line is true only if $\gamma=1$. Therefore, the case of upper boundary pressure (with $\bar{x}=0$ and $f_{t}=0$ ) implies no lobbying by the offshore country, irrespective of its efficiency level $\rho$. Also intuitively this makes sense: if the onshore country commits to eliminate profit shifting and thereby leads to no tax revenue for the offshore country, conducting expensive profit shifting is dominated by not doing anything.

Parameter restrictions One might also be concerned whether $\gamma^{*}$ exceeds values of one or falls below values of zero. Regarding the previous, a transformation of equation (11) is insightful:

$$
\begin{aligned}
\gamma^{*} & =\frac{9 k h \rho-2 \alpha k}{9 k h \rho-2 \alpha^{2} h}=\frac{9 k h \rho-2 \alpha k-2 \alpha^{2} h+2 \alpha^{2} h}{9 k h \rho-2 \alpha^{2} h} \\
\Leftrightarrow \gamma^{*} & =1-\frac{2 \alpha k-2 \alpha^{2} h}{9 k h \rho-2 \alpha^{2} h}
\end{aligned}
$$

As is visible from equation (33b), $\gamma$ is one, i.e. the second term vanishes, if $\alpha^{u p}=\frac{k}{h}$. It is also rather straightforward that for any values below $\alpha^{u p}, \gamma$ is lower than one. This is the case as $2 \alpha k>2 \alpha^{2} h \forall \alpha \in\left(0 ; \frac{k}{h}\right)$.

To avoid that $\gamma$ becomes zero or negative, I assume throughout that $\rho>\max \left[\frac{2 \alpha}{9 h} ; \frac{2 \alpha^{2}}{9 k}\right]$. This ensures that both the numerator in equation (33a) and the denominator in equation (33b) are always larger than zero. 


\section{A.2. Comparative statics}

As the equilibrium values of $\gamma^{*}$ and $\alpha^{*}$ are only implicitly given, the implicit function theorem is necessary to evaluate the comparative statics for the given equilibrium values. Hence, the matrix of second order (cross-) derivatives is given by $|D|$, where

$$
|D|=\left|\begin{array}{ll}
\frac{\partial^{2} W_{H}}{\partial \alpha^{2}} & \frac{\partial^{2} W_{H}}{\partial \alpha \partial \gamma} \\
\frac{\partial^{2} W_{F}}{\partial \gamma \partial \alpha} & \frac{\partial^{2} W_{F}}{\partial \gamma^{2}}
\end{array}\right|=\left|\begin{array}{cc}
\frac{2 \gamma^{2} h}{9 k}-g & \frac{4}{9}+\frac{4 \alpha \gamma h}{9 k} \\
-\frac{2}{9 h}+\frac{4 \alpha \gamma}{9 k} & \frac{2 \alpha^{2}}{9 k}-\rho
\end{array}\right|
$$

In order to arrive at conditions for this determinant to be either positive or negative, taking a closer look yields:

$$
|D|=\underbrace{\left(\frac{2 \gamma^{2} h}{9 k}-g\right)}_{-} \underbrace{\left(\frac{2 \alpha^{2}}{9 k}-\rho\right)}_{-}-\underbrace{\left(-\frac{2}{9 h}+\frac{4 \alpha \gamma}{9 k}\right)}_{\text {ambiguous }} \underbrace{\left(\frac{4}{9}+\frac{4 \alpha \gamma h}{9 k}\right)}_{+} \gtreqless 0 .
$$

The first part of the determinant is negative, as this imposed by assuming $g>\frac{2 \gamma^{2} h}{9 k}$. The second part has to be negative: Assuming that one starts at the equilibrium value of $\gamma$, an increase in $\gamma$ leads to a negative first order condition, as lowering $\gamma$ further yields more benefits. The third term is positive if it holds that $\frac{\alpha \gamma}{k}<\frac{1}{2 h}$, i.e. if the effective pressure component on the firm relative to financial market frictions is smaller in size than $\frac{1}{2 h}$. The last term is unambiguously positive.

Assuming that direct effects are larger in size than indirect ones, $|D|>0$ is used for further computations. 